Short Communication

\title{
Effect of melatonin on the behaviour of rats with continuous light-induced hypertension
}

\author{
Kristina Repova ${ }^{1}$, Kristina Krajcirovicova ${ }^{1}$, Martina Mullerova ${ }^{1}$, Silvia Aziriova ${ }^{1}$, Tomas \\ Baka $^{1}$, Stefan Zorad ${ }^{2}$, Peter Slavkovsky ${ }^{1}$, Julius Hodosy ${ }^{3}$, Peter Celec ${ }^{1,3}$, Michaela Adamcova, \\ Ludovit Paulis ${ }^{1,5}$ and Fedor Simko ${ }^{1,2,6}$ \\ ${ }^{1}$ Institute of Pathophysiology, Faculty of Medicine, Comenius University, Bratislava, Slovakia \\ ${ }^{2}$ Institute of Experimental Endocrinology, Biomedical Research Center, Slovak Academy of Sciences, Bratislava, Slovakia \\ ${ }^{3}$ Institute of Molecular Biomedicine, Faculty of Medicine, Comenius University, Bratislava, Slovakia \\ ${ }^{4}$ Department of Physiology, School of Medicine, Charles University, Hradec Kralove, Czech Republic \\ ${ }^{5}$ Institute of Normal and Pathological Physiology, Slovak Academy of Sciences, Bratislava, Slovakia \\ ${ }^{6} 3^{\text {rd }}$ Department of Internal Medicine, Faculty of Medicine, Comenius University, Bratislava, Slovakia
}

\begin{abstract}
This study investigated whether continuous light exposure (CLE) results in behavioural disturbances in rats and whether melatonin can modify these potential changes. Four groups of 3-month-old Wistar rats were treated as follows for six weeks: control, melatonin, CLE, and CLE with melatonin. CLE increased systolic blood pressure and melatonin reduced it. No changes in behavioural patterns by CLE were observed. In the controls, melatonin reduced both exploration and locomotion but these parameters remained uninfluenced in the CLE. We conclude that melatonin exerted a different impact on behaviour in controls and in the CLE group.
\end{abstract}

Key words: Melatonin - Behaviour - Continuous light - Hypertension

Artificial light at night is a source of light pollution that may result in the disruption of circadian rhythms and the suppression of nocturnal melatonin production by the pineal gland. Circadian disruption has been implicated in multiple psychiatric disorders like anxiety, bipolar disorder or schizophrenia (Smolensky et al. 2015). In experimental conditions, the exposure of animals to continuous light mimics the exposure of humans to artificial lighting (Simko et al. 2013). Continuous illumination is associated with a number of structural and functional alterations of the pineal gland (Fujioka et al. 2011; Litvinenko et al. 2011) including the suppression of the production and the release of melatonin, downregulating thus the nocturnal surge of melatonin levels (Simko et al. 2013). Melatonin deficiency results in sleep disturbances (Xie et al. 2017), neurodegenerative disorders (Wu et al. 2003), and other pathological conditions such as

Correspondence to: Fedor Simko, Institute of Pathophysiology, Faculty of Medicine, Comenius University, Sasinkova 4, 81372 Bratislava, Slovakia

E-mail: fedor.simko@fmed.uniba.sk hypertension development (Simko et al. 2014a). Eventually, these alterations could result in behavioural disorders.

The aim of this experiment was to show whether continuous light exposure induces behavioural disturbances in rats and whether melatonin administration could modify these potential alterations.

All experimental procedures were carried out in accordance with the Guide for the Care and Use of Laboratory Animals published by the US National Institute of Health (NIH Publication No 8523, revised 1985). Male adult (three-month-old) Wistar rats (Dobra Voda, Slovakia) were randomly divided into four groups ( $n=10$ per group): agematched control (Wistar) rats (LD), rats treated with melatonin (10 mg/kg/day; Sigma Chemical Co., Deisenhofen, Germany; LD+Mel), rats exposed to $24 \mathrm{~h}$ /day continuous light (LL) and rats exposed to $24 \mathrm{~h}$ /day continuous light treated with melatonin $(10 \mathrm{mg} / \mathrm{kg} /$ day; LL+Mel). Melatonin was dissolved in drinking water and its concentration was adjusted to daily water consumption to ensure the correct dosage. Melatonin containing solutions were protected from light by using black bottles. Rats were kept in individual cages 
at $22-24^{\circ} \mathrm{C}$ (the temperature was maintained at constant level by air conditioning system) and fed with a regular pellet diet ad libitum. Systolic blood pressure (SBP) was measured each week by noninvasive tail-cuff plethysmography (Hugo-Sachs Elektronik, Freiburg, Germany). In the home cages, the light intensity was 500 lux to simulate the office workplace conditions, while during the open field testing it was reduced to 150 lux to adapt light conditions used in other laboratories during open field testing (Aubrecht et al. 2013; Okuliarova et al. 2016).

During the six weeks of the experiment, the behavioural parameters were measured by open field test each week to determine locomotion and exploration. The open field test consisted of a device in the shape of a $1 \times 1 \mathrm{~m}$ square with sidewalls $0.5 \mathrm{~m}$ in height and virtually divided into 16 squares. Each animal was placed in the central part, and was permitted to freely explore the field for 5 minutes. The total horizontal activity (number of squares crossed) and vertical activity (number of instances of rearing up on hind legs) were monitored. The results were expressed as the percentage change relative to the scores of the first week.

Results are expressed as mean \pm standard error of mean (SEM). For statistical analysis a one-way, two-tailed analysis of variance (ANOVA) and the Bonferroni post-hoc test were used for SBP and LSD (Fisher's least significant difference) test was used for statistical analysis of behaviour. The differences were considered significant if the value $p<0.05$.

After six weeks of treatment, SBP was $125 \pm 0.79 \mathrm{mmHg}$ in the control group and was increased by $29 \%(p<0.05)$ in the LL group. SBP decreased significantly by melatonin treatment (by $15 \%, p<0.05$ ) compared to the LL group (Figure 1).

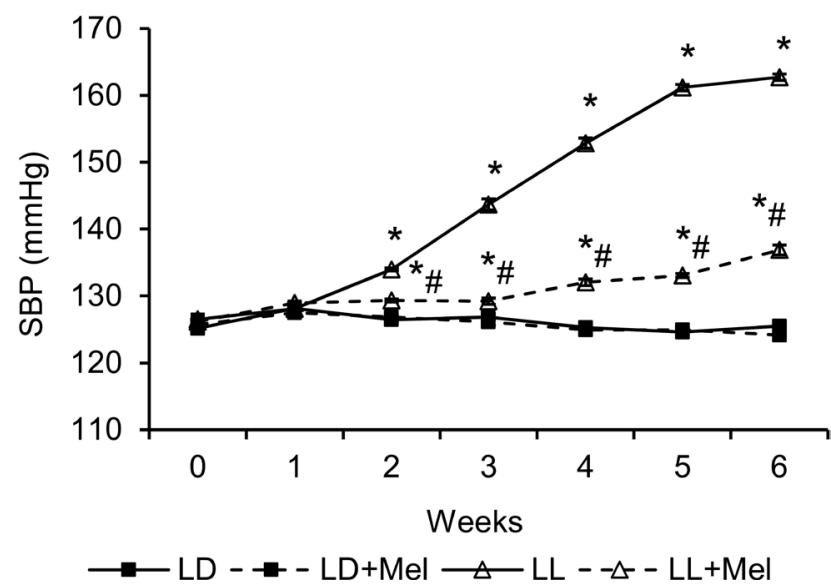

Figure 1. The effect of continuous light exposure (LL) and melatonin $(\mathrm{LD}+\mathrm{Mel})$ administration on systolic blood pressure (SBP) during 6 weeks of treatment. LD, controls; LL+Mel, rats exposed to continuous light and treated with melatonin. ${ }^{*} p<0.05 v \mathrm{~s}$. LD, ${ }^{\#} p<0.05$ vs. LL.
During six weeks of treatment, neither horizontal nor vertical activities of rats were altered by continuous light exposure (Figure 2A, 2B). In the control animals, melatonin reduced both horizontal (by 63\%, $p<0.05$ ) and vertical activity (by $71 \%, p<0.05$ ) (Figure $2 \mathrm{C}, \mathrm{D}$ ). In rats exposed to continuous light, melatonin had no effect on horizontal and vertical activity (Figure 2E,F).

Melatonin is predominantly released during the darkphase of the day (Klein and Weller 1970). In addition to its specific receptor-induced effects, melatonin has a number of direct, pleiotropic actions such as antioxidative, antiinflammatory and antiproliferative effects (Reiter et al. 2016; Dominguez-Rodriguez et al. 2017), which protect the heart, vasculature (Simko and Paulis 2007; Simko and Pechanova 2009; Simko et al. 2016; Repova-Bednarova et al. 2013) and other systems (Aziriova et al. 2014; Hrenak et al. 2015; Opie et al. 2016).

Inappropriate nocturnal illumination can disrupt the circadian rhythms, which may be harmful due to the inhibition of the nocturnal melatonin secretion. Shift or night work was shown to be associated with an increased risk of variable pathological conditions such as cancer, cardiovascular disturbances, diabetes and obesity development (Touitou et al. 2017). In experimental animals, it has been repeatedly shown that chronic continuous light exposure results in systolic hypertension development and left ventricular fibrotic remodelling (Simko et al. 2010, 2014b). In our experiment, the continuous light exposure was not accompanied by significant changes in locomotion or exploration. However, the literal data are quite controversial in this area. Some authors suggest that chronic exposure to continuous light leads to anxious and depressive behaviour in rats (Roman and Karlsson 2013; Tapia-Osorio et al. 2013), while others revealed reduced anxiety-like behaviour in rats as an adaptation to stress (Fonken et al. 2009). These data differences might have been determined by genetic variances of laboratory animals, the duration and intensity of continuous light exposure, as well as by variable methodological approaches. In this experiment, melatonin reduced both locomotion and exploration in the control rats; however, it had no significant effect on the behaviour in rats exposed to continuous light. The different impact of melatonin in rats in the control and continuous light-exposed groups might have been determined by its potentially different levels. Apparently, the control rats (that had normal levels of melatonin) may have reached a high, non-physiological, level by melatonin treatment resulting in a sedative effect as observed previously (Jan et al. 2011). On the other hand, in chronic illumination obviously associated with melatonin deficiency (Simko et al. 2013), the melatonin level might have been only partially corrected by chronic melatonin treatment. Furthermore, based on our findings, it may be supposed that SBP alterations did not 
contribute to behavioural patterns in continuous illumination or during treatment with melatonin.

We conclude that continuous light exposure did not change the horizontal and vertical activities of rats. Mela- tonin exerted a different impact on behaviour in the control group and in the group exposed to continuous light.

Limitations: The repeated measurements of behavioural manifestations were done with the aim to reflect the poten-
A

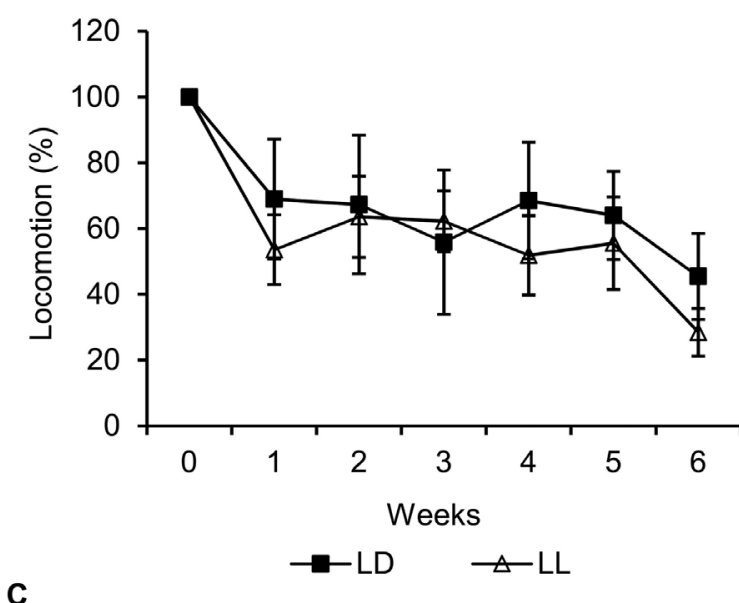

C

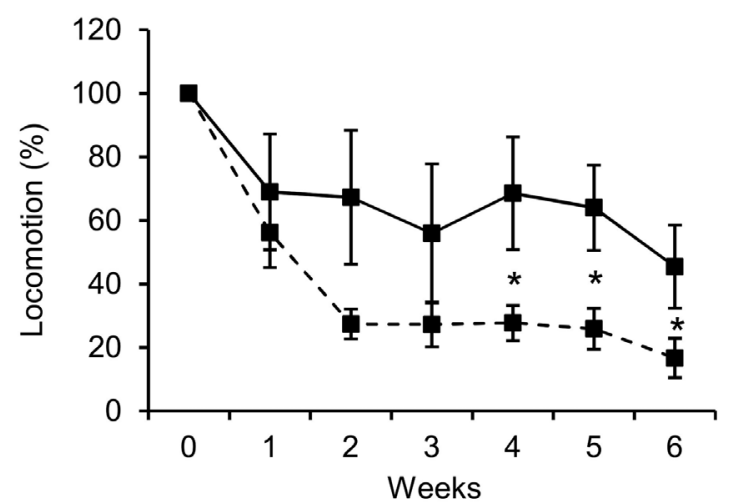

E

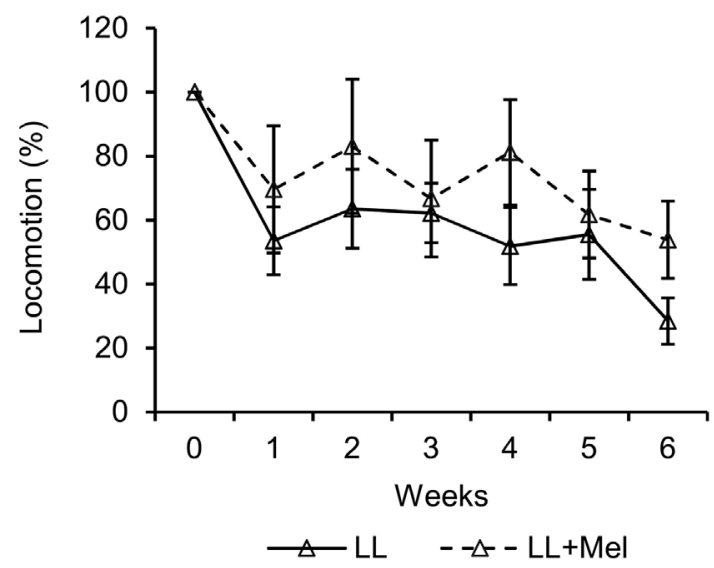

B

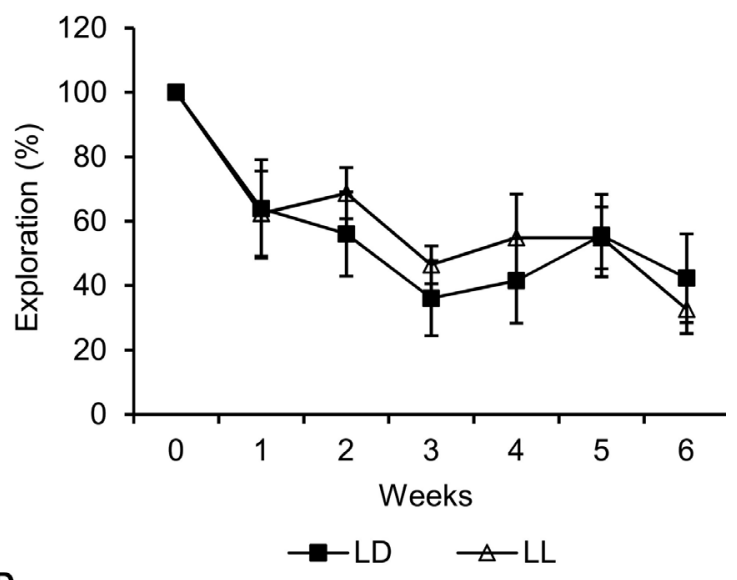

D
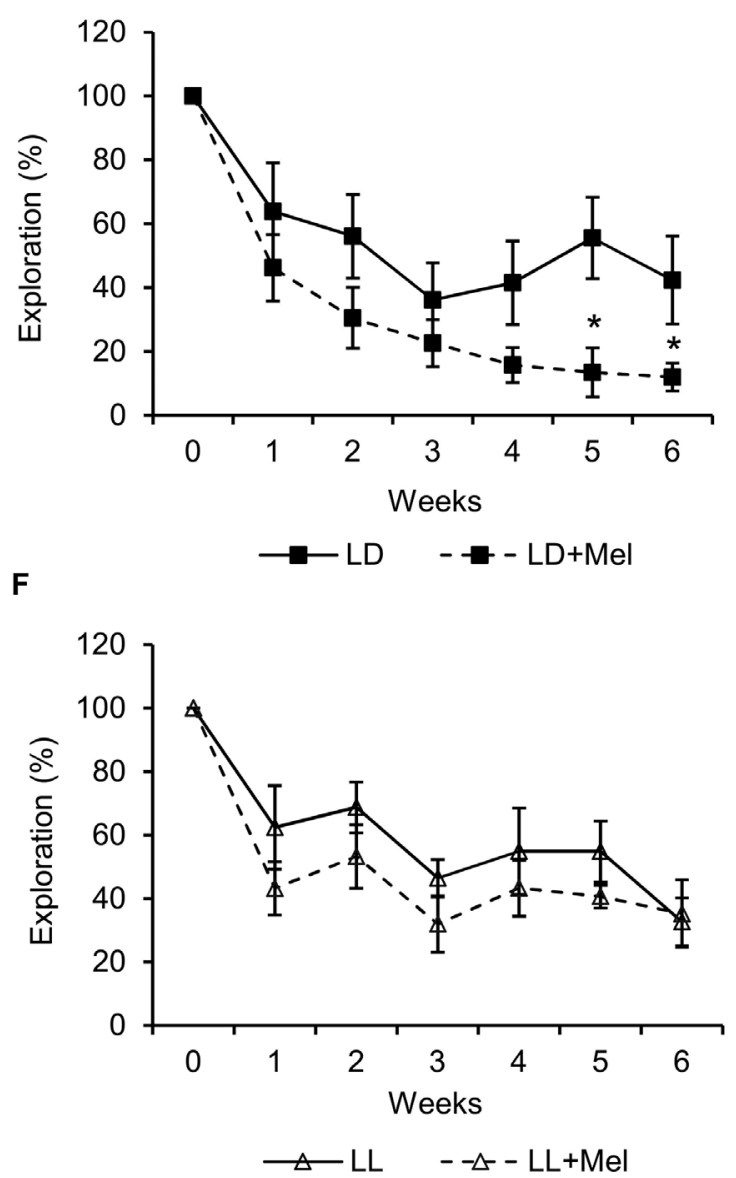

Figure 2. The effect of continuous light exposure (LL) on horizontal (locomotion) (A) and vertical (exploration) (B) activity, the effect of melatonin (LD+Mel) administration on horizontal (C) and vertical (D) activity, and the effect of continuous light exposure and melatonin $(\mathrm{LL}+\mathrm{Mel})$ administration on horizontal $(\mathbf{E})$ and vertical $(\mathbf{F})$ activity. $\mathrm{LD}$, controls. ${ }^{*} p<0.05$ vs. LD. 
tial effect of prolonged lightening and melatonin treatment on behaviour. Although the repeated measurements were done in a relatively long time gap of one week, the effect of habituation is not possible to be excluded.

Melatonin's sedative effects might be expected to influence not only locomotor and exploratory behaviour but even more the anxiety-like behaviour; thus elevated plus maze might have bring interesting data. However, this investigation was beyond the scope of this experiment.

Conflicts of interest. The authors declare that they have no conflict of interest.

Acknowledgments. This work was supported by following grants for scientific research: VEGA 1/0071/15, VEGA 2/0195/15, UK/96/2015 and by Programme PROGRES Q 40/5.

\section{References}

Aubrecht TG, Weil ZM, Magalang UJ, Nelson RJ (2013): Dim light at night interacts with intermittent hypoxia to alter cognitive and affective responses. Am. J. Physiol. Regul. Integr. Comp. Physiol. 305, R78-86 https://doi.org/10.1152/ajpregu.00100.2013

Aziriova S, Repova K, Bednarova K, Krajcirovicova K, Hrenak J, Rajkovicova R, Arendasova K, Kamodyova N, Celec P, Zorad $S$, et al. (2014): Doxorubicin-induced behavioral disturbances in rats: protective effect of melatonin and captopril. Pharmacol. Biochem. Behav. 124, 284-289 https://doi.org/10.1016/j.pbb.2014.06.021

Dominguez-Rodriguez A, Abreu-Gonzalez P, de la TorreHernandez JM, Gonzalez-Gonzalez J, Garcia-Camarero T, Consuegra-Sanchez L, Garcia-Saiz MD, Aldea-Perona A, Virgos-Aller T, Azpeitia A, Reiter RJ, MARIA Investigators (2017): Effect of intravenous and intracoronary melatonin as an adjunct to primary percutaneous coronary intervention for acute ST-elevation myocardial infarction: Results of the melatonin adjunct in the acute myocardial infarction treated with angioplasty trial. J. Pineal Res. 62, e12374 https://doi.org/10.1111/jpi.12374

Fonken LK, Finy MS, Walton JC, Weil ZM, Workman JL, Ross J, Nelson RJ (2009): Influence of light at night on murine anxiety- and depressive-like responses. Behav. Brain Res. 205, 349-354 https://doi.org/10.1016/j.bbr.2009.07.001

Fujioka A, Fujioka T, Tsuruta R, Izumi T, Kasaoka S, Maekawa T (2011): Effects of a constant light environment on hippocampal neurogenesis and memory in mice. Neurosci. Lett. 488, 41-44 https://doi.org/10.1016/j.neulet.2010.11.001

Hrenak J, Paulis L, Repova K, Aziriova S, Nagtegaal EJ, Reiter RJ, Simko F (2015): Melatonin and renal protection: novel perspectives from animal experiments and human studies. Curr. Pharm. Des. 21, 936-949 https://doi.org/10.2174/1381612820666140929092929

Jan JE, Reiter RJ, Wong PK, Bax MC, Ribary U, Wasdell MB (2011): Melatonin has membrane receptor-independent hypnotic action on neurons: an hypothesis. J. Pineal Res. 50, 233-240 https://doi.org/10.1111/j.1600-079X.2010.00844.x

Klein DC, Weller JL (1970): Indole metabolism in the pineal gland: a circadian rhythm in $\mathrm{N}$-acetyltransferase. Science 169, 1093-1095

https://doi.org/10.1126/science.169.3950.1093

Litvinenko GI, Shurlygina AV, Gritsyk OB, Mel'nikova EV, Tenditnik MV, Avrorov PA, Trufakin VA (2015): Effects of melatonin on morphological and functional parameters of the pineal gland and organs of immune system in rats during natural light cycle and constant illumination. Bull. Exp. Biol. Med. 159, 732-735 https://doi.org/10.1007/s10517-015-3061-Z

Okuliarova M, Molcan L, Zeman M (2016): Decreased emotional reactivity of rats exposed to repeated phase shifts of light-dark cycle. Physiol. Behav. 156, 16-23 https://doi.org/10.1016/j.physbeh.2016.01.003

Opie LH, Lecour S (2016): Melatonin has multiorgan effects. Eur. Heart J. Cardiovasc. Pharmacother. 2, 258-265 https://doi.org/10.1093/ehjcvp/pvv037

Reiter RJ, Mayo JC, Tan DX, Sainz RM, Alatorre-Jimenez M, Qin L (2016): Melatonin as an antioxidant: under promises but over delivers. J. Pineal Res. 61, 253-278 https://doi.org/10.1111/jpi.12360

Repova-Bednárova K, Aziriova S, Hrenak J, Krajcirovicova K, Adamcova M, Paulis L, Simko F (2013): Effect of captopril and melatonin on fibrotic rebuilding of the aorta in 24 hour lightinduced hypertension. Physiol. Res. 62, S135-S141

Roman E, Karlsson O (2013): Increased anxiety-like behavior but no cognitive impairments in adult rats exposed to constant light conditions during perinatal development. Ups. J. Med. Sci. 118, 222-227 https://doi.org/10.3109/03009734.2013.821191

Simko F, Paulis L (2007): Melatonin as a potential antihypertensive treatment. J. Pineal Res. 42, 319-322 https://doi.org/10.1111/j.1600-079X.2007.00436.x

Simko F, Pechanova O (2009): Recent trends in hypertension treatment: perspectives from animal studies. J. Hypertens. Suppl. 27, S1-S4 https://doi.org/10.1097/01.hjh.0000358829.87815.d4

Simko F, Pechanova O, Pelouch V, Krajcirovicova K, Celec P, Palffy R, Bednarova K, Vrankova S, Adamcova M, Paulis L (2010): Continuous light and L-NAME-induced left ventricular remodelling: different protection with melatonin and captopril. J. Hypertens. 28, S13-S18 https://doi.org/10.1097/01.hjh.0000388489.28213.08

Simko F, Reiter R. J, Pechanova O, Paulis L (2013): Experimental models of melatonin-deficient hypertension. Front. Biosci. $18,616-625$ https://doi.org/10.2741/4125

Simko F, Bednarova KR, Krajcirovicova K, Hrenak J, Celec P, Kamodyova N, Gajdosechova L, Zorad S, Adamcova M (2014a): Melatonin reduces cardiac remodeling and improves survival in rats with isoproterenol-induced heart failure. J. Pineal Res. 57, 177-184 https://doi.org/10.1111/jpi.12154

Simko F, Pechanova O, Repova Bednarova K, Krajcirovicova K, Celec P, Kamodyova N, Zorad S, Kucharska J, Gvozdjakova A, 
Adamcova M, Paulis L (2014b): Hypertension and cardiovascular remodelling in rats exposed to continuous light: protection by ACE-inhibition and melatonin. Mediators. Inflamm. 2014, 703175 https://doi.org/10.1155/2014/703175

Simko F, Baka T, Paulis L, Reiter RJ (2016): Elevated heart rate and nondipping heart rate as potential targets for melatonin: a review. J. Pineal Res. 61, 127-137 https://doi.org/10.1111/jpi.12348

Smolensky MH, Sackett-Lundeen LL, Portaluppi F (2015): Nocturnal light pollution and underexposure to daytime sunlight: Complementary mechanisms of circadian disruption and related diseases. Chronobiol. Intern. 8, 1029-1048 https://doi.org/10.3109/07420528.2015.1072002

Tapia-Osorio R, Salgado-Delgado M, Angeles-Castellanos M, Escobar C (2013): Disruption of circadian rhythms due to chronic constant light leads to depressive and anxiety-like behaviors in the rat. Behav. Brain Res. 252, 1-9 https://doi.org/10.1016/j.bbr.2013.05.028
Touitou Y, Reinberg A, Touitou D (2017): Association between light at night, melatonin secretion, sleep deprivation, and the internal clock: Health impacts and mechanisms of circadian disruption. Life Sci. 15, 94-106 https://doi.org/10.1016/j.lfs.2017.02.008

Wu YH, Feenstra MG, Zhou JN, Liu RY, Toranõ JS, Van Kan HJ, Fischer DF, Ravid R, Swaab DF (2003): Molecular changes underlying reduced pineal melatonin levels in Alzheimer disease: alterations in preclinical and clinical stages. J. Clin. Endocrinol. Metab. 88, 5898-5906 https://doi.org/10.1210/jc.2003-030833

Xie Z, Chen F, Li WA, Geng X, Li C, Meng X, Feng Y, Liu W, Yu F (2017): A review of sleep disorders and melatonin. Neurol. Res. 39, 559-565

https://doi.org/10.1080/01616412.2017.1315864

Received: October 4, 2017

Final version accepted: December 12, 2017

First published online: June 29, 2018 